\title{
EDUCAÇÃO COMUM OU ESPECIAL? ANÁLISE DAS DIRETRIZES POLÍTICAS DE EDUCAÇÃO ESPECIAL BRASILEIRAS ${ }^{1}$
}

\author{
¿EDUCACIÓN COMÚN O ESPECIAL? ANALLISIS DE LAS DIRECTRICES DE LA \\ POLÍTICA DE EDUCACIÓN ESPECIAL DE BRASIL
}

\author{
COMMON OR SPECIAL EDUCATION? ANALYSIS OF BRAZILIAN SPECIAL \\ EDUCATION POLICY GUIDELINES
}

Marcia Denise PLETSCH ${ }^{2}$

Flávia Faissal de SOUZA ${ }^{3}$

RESUMO: A partir de uma pesquisa documental sobre as diferentes diretrizes políticas de Educação Especial elaboradas pelos governos brasileiros nos anos de 1994, 1999, 2001, 2008 e 2020, este artigo objetiva discutir as mudanças conceituais e terminológicas para referir-se ao público da Educação Especial no país, assim como os suportes educacionais oferecidos para a Educação dessa população. Nossas análises apontam que, nos documentos de 1994 a 2008, houve avanços em termos de garantia de direitos educacionais numa perspectiva inclusiva ao incorporar princípios do modelo social da deficiência em detrimento do modelo médico. Também se fortaleceu e se ampliou o número de matrículas de pessoas com deficiência na educação básica e superior pública. No entanto, em setembro de 2020, o governo federal publicou um decreto que institui uma nova Política de Educação Especial, poucas semanas depois suspensa por medida cautelar do Supremo Tribunal Federal, sob a alegação de que o decreto volta a privilegiar a segregação em instituições filantrópicas privadas. Entre outros aspectos, a proposta pega carona no discurso econômico liberal de desresponsabilização do Estado, segundo o qual as famílias teriam o direito de "escolher" o tipo de educação que desejam para os filhos.

PALAVRAS-CHAVE: Políticas de educação inclusiva. Educação especial. Deficiência.

RESUMEN: A partir de una investigación documental sobre los diferentes lineamientos de política de Educación Especial desarrollados por los gobiernos brasileños en los años de 1994, 1999, 2001, 2008 y 2020, este artículo tiene como objetivo discutir los cambios conceptuales y terminológicos para referirse al público de la Educación Especial en el país, así como el apoyo educativo que se ofrece para la educación de esta población. , Nuestros

\footnotetext{
${ }^{1} \mathrm{O}$ artigo integra projeto de pesquisa registrada no comitê de ética da Universidade Federal Rural do Rio de Janeiro (UFRRJ) sob o Processo $n^{\circ}$ 23083.031153/2019-40.

${ }^{2}$ Universidade Federal Rural do Rio de Janeiro (UFRRJ), Nova Iguaçu - RJ - Brasil. Professora Associada do Departamento Educação e Sociedade, do Programa de Pós-Graduação em Educação, Contextos Contemporâneos e Demandas Populares e do Programa de Pós-Graduação em Humanidades Digitais. Doutorado em Educação (UERJ). Bolsista de Produtividade em Pesquisa do CNPq - Nível 2. ORCID: https://orcid.org/0000-0001-59060487. E-mail: marciadenisepletsch@gmail.com

${ }^{3}$ Universidade do Estado do Rio de Janeiro (UERJ), Rio de Janeiro - RJ - Brasil. Professora Adjunta do Departamento de Formação de Professores, do Programa de Pós-Graduação em Educação, Cultura e Comunicação em Periferias Urbanas e do Programa de Pós-graduação em Educação. Doutorado em Educação (UNICAMP). ORCID: https://orcid.org/0000-0003-0225-8358. E-mail: flaviasouza.uerj@gmail.com
}

RIAEE - Revista Ibero-Americana de Estudos em Educação, Araraquara, v. 16, n. esp. 2, p. 1286-1306, maio 2021. e-ISSN: 1982-5587 DOI: https://doi.org/10.21723/riaee.v16iesp2.15126 
análisis señalan que, en los documentos de 1994 a 2008, hubo avances en la actualidad en materia de garantía de los derechos educativos en una perspectiva inclusiva al incorporar principios del modelo social de discapacidad en detrimento del modelo médico. También se fortaleció y se amplió el número de matrículas de personas con discapacidad en la educación pública básica y superior. Sin embargo, en septiembre de 2020, el gobierno federal publicó un decreto que instituye una nueva Politica de Educación Especial, unas semanas después suspendida por medida cautelar del Supremo Tribunal Federal, con el argumento de que el decreto vuelve a privilegiar la segregación en instituciones asistenciales privadas. Entre otros aspectos, una propuesta se engancha en el discurso económico liberal de la responsabilidad del Estado, según el cual las familias tendrían el derecho a "elegir" el tipo de educación que quieren para sus hijos.

PALABRAS CLAVE: Políticas de educación inclusiva. Educación especial. Discapacidad.

ABSTRACT: Based on a documental research on the different brazilians governments Special Education policy guidelines in the documents of 1994, 1999, 2001, 2008 and 2020, this article aims to discuss the conceptual and terminological changes to refer to the Special Education public in the country, as well as the educational support offered for the education of this population. Our analysis points that the documents from 1994 to 2008 indicate advances in terms of guaranteeing educational rights from an inclusive perspective by incorporating principles of the social model of disability to the detriment of the medical model. It has also strengthened and expanded the enrollment of people with disabilities in basic and higher public education. However, in September 2020, the current government published a decree establishing a new Special Education Policy, few weeks later suspended by a Supreme Court precautionary measure, which again favors segregation in private assistance institutions. Among other aspects, the proposal takes a ride on the liberal economic discourse of disclaiming responsibility of the state, according to which families would have the right to "choose" the type of education they want for their children.

KEYWORD: Inclusive education policy. Special education. Disability.

\section{Introdução}

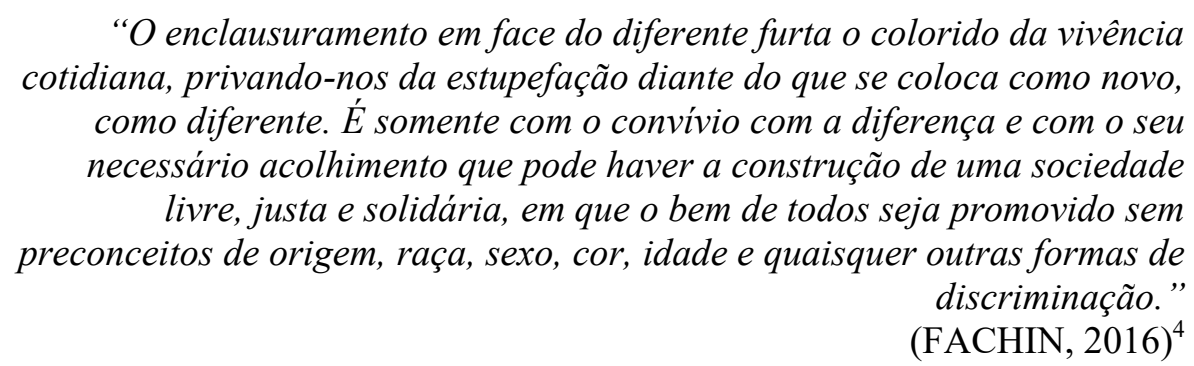

A disputa sobre o lócus da escolarização de pessoas com deficiência no Brasil historicamente tem sido tensionada entre a educação pública e a educação segregada em

\footnotetext{
${ }^{4}$ Ministro do Supremo Tribunal Federal no texto da medida cautelar na Ação Direta de Inconstitucionalidade ${ }^{\circ}$
} 5.357/DF, 2016. 
instituições filantrópicas privadas, como evidenciado por Laplane, Caiado e Kassar (2016). O tensionamento entre a escola comum e especial foi título do livro publicado em 1986 pelo professor Marcos Mazzotta. Passados mais de 30 anos retomamos aqui essa discussão agora sob novas bases, focando nos princípios da educação inclusiva que analisamos à luz dos Direitos Humanos (DINIZ; BARBOSA; SANTOS, 2009; KASSAR, 2016; KASSAR; REBELO; OLIVEIRA, 2019; PLETSCH, 2020). Nessa perspectiva a política de inclusão educacional compreende que os sujeitos com deficiência devem ter acesso à educação, participar das atividades educativas e aprender. Isso implica a combinação de três elementos: 1) o reconhecimento da diferença como constitutiva do humano; b) as especificidades no desenvolvimento dos sujeitos; e, 3) a convivência com a diversidade cultural, numa escola/universidade com todos e para todos.

Como essa disputa entre setores privados e públicos vem sendo tratada e incorporada nas diretrizes federais de Educação Especial é o objeto deste artigo. Igualmente, pretendemos discutir as mudanças epistemológicas na compreensão do fenômeno da deficiência, que sai de uma perspectiva biomédica na década de 1990 para um modelo social pautado nos Direitos Humanos nos anos dois mil, em conformidade com os avanços das políticas de educação inclusiva. Para tal, em termos metodológicos, propomos uma análise de documentos que tratam das diretrizes políticas de Educação Especial elaboradas por governos brasileiros, a saber: a) 1994 - Política Nacional de Educação Especial; b) 1999 - Política Nacional para a Integração da Pessoa Portadora de Deficiência; c) 2001 - Diretrizes Nacionais para Educação Especial na Educação Básica; d) 2008 - Política Nacional de Educação Especial na Perspectiva da Educação Inclusiva; e) 2020 - Política Nacional de Educação Especial: Equitativa, Inclusiva e com Aprendizagem ao Longo da Vida.

Nossa análise toma como referência as disposições contidas nestes documentos sobre a indicação do espaço da educação dos alunos da Educação Especial, o sistema de suportes educacionais e a definição de quem seria o público da Educação Especial. Para essa discussão faremos diálogo com a produção científica da área e os documentos nacionais e internacionais sobre a educação inclusiva, organizando o texto em três eixos: a) Educação para Todos: avanços, contradições e disputas políticas; b) educação inclusiva como princípio dos Direitos Humanos para a educação de pessoas com deficiência; e, c) Direitos Humanos em risco: o desmonte da proposta de educação inclusiva. 


\section{Educação para Todos: avanços, contradições e disputas políticas}

Após o período da ditadura cívico-militar (1961-1985) tivemos a promulgação da Constituição de 1988 com ampla participação popular. No processo de elaboração deste documento, diferentes grupos sociais, que viviam apartados de seus direitos e buscavam uma participação mais efetiva na sociedade e nas decisões políticas a eles concernentes, tiveram ganhos importantes. Como afirma Gohn (2005, p. 8), a luta dos "não cidadãos” foi alavancada pela base jurídico-legislativa desta Constituição.

A constituinte representou um avanço significativo nos direitos sociais e educacionais da população brasileira. Dentre as conquistas: a assunção da educação como um direito social; a universalização da educação obrigatória compulsória, pública e gratuita, garantindo, ao menos legalmente, a educação das pessoas que não tinham acesso ao sistema escolar público; o estabelecimento de princípios da educação do aluno com deficiência no ensino regular; a implantação do sistema comum de suporte complementar ou suplementar para garantir a inserção das pessoas com deficiência no processo de ensino-aprendizagem; a implantação do regime de colaboração entre a União, os estados, o Distrito Federal e os municípios, instituindo a descentralização (LANNA JUNIOR, 2010; KASSAR, 2011).

Contudo, ainda para a Educação Especial a disputa histórica entre a educação pública e as instituições segregadas filantrópicas privadas ficou explicitada na adoção do termo preferencialmente para referir-se à educação dessa parcela da população na rede regular de ensino. Em relação às parcerias público-privadas, Minto $(2012$, s/p) vai apontar que, contraditoriamente aos avanços sociais, foi também a Constituição, sobretudo no campo educacional, que "não garantiu a exclusividade de recursos públicos para os estabelecimentos de ensino mantidos pelo Estado, abrindo uma brecha - que, aliás, ainda não foi fechada - para o setor privado apropriar-se de novas fatias do fundo público para a educação".

Não distante, no contexto da crise econômica da década de 1990, a disseminação internacional do ideário de uma "sociedade para todos" cresceu. Já em pauta em debates no escopo do Sistema da Organização das Nações Unidas, os preceitos de "uma educação para todos" sustentando pelos princípios de uma Educação Especial não segregada foi anunciada. Em 1993, no documento Regras Padrões sobre Equalização de Oportunidades para Pessoas com Deficiências (A/RES/48/96) (UNGA, 1994), na Sessão 48, Regra 6 - Educação, foi afirmado que a educacão de pessoas com deficienncia deve ser de responsabilidade dos Estados, inserida nos sistemas regulares de ensino. 
Nesta esteira, a Declaração de Salamanca, lançada em 1994, na Conferência Mundial sobre Necessidades Educacionais Especiais: acesso e qualidade, organizada pela UNESCO, com a participação de 92 países e inúmeras organizações não governamentais, instituiu a disseminação ampla do conceito de educação inclusiva, passando a influenciar a elaboração de políticas públicas educacionais direcionadas para pessoas com deficiência. Neste documento, apresentava-se a ideia da garantia dos Direitos Humanos, ressaltando o “compromisso em prol da Educação para Todos, reconhecendo a necessidade e a urgencia de garantir a educação para as crianças, jovens e adultos com necessidades educativas especiais no quadro do sistema regular de educação" (UNESCO, 1998, p. 2). Reconhecia-se, assim, que as pessoas com deficiência têm o direito de aprender inseridas em processos educacionais nos quais suas necessidades específicas sejam atendidas. Sendo que, as escolas comuns representam o meio mais eficaz de combater atitudes discriminatórias, de criar comunidades acolhedoras, construir uma sociedade pautada no respeito à diferença e dar educação para todos; além disso, proporcionam uma educação efetiva à maioria das crianças e melhoram a eficiência, a relação custo-benefício de todo sistema educativo.

Nesse contexto, em 1994, no Brasil, foi lançada a Política Nacional de Educação Especial, que, segundo a publicação, foi amplamente discutida com o movimento da sociedade civil. A fim de garantir o atendimento educacional, neste documento foram estabelecidos objetivos gerais e específicos referentes à “interpretação dos interesses, necessidades e aspirações de pessoas portadoras de deficiências, condutas típicas e altas habilidades" (BRASIL, 1994, p. 7). Em relação aos tipos de suportes e serviços, este documento apresenta um amplo espectro, que de certa forma aponta para o tensionamento entre as concepções de deficiência e de Educação Especial que circulavam na época, tais como: atendimento domiciliar, classe comum, classe especial, classe hospitalar, centro integrado de educação especial, professor itinerante, escola especial, oficina pedagógica, estimulação essencial e sala de recursos.

Lima e Mendes (2009), ao analisar esse documento, destacam como principais características: a concepção da Educação Especial como transversal, permeando todos os níveis e modalidades de educação; seu caráter complementar ao ensino regular, ainda segundo a autora; a responsabilização das instituições especializadas no oferecimento dos serviços educacionais complementares ao sistema de ensino regular - por meio da parceria públicoprivada, na qual é possibilitado para a efetivação o repasse tanto de verbas como de recursos

${ }^{5}$ Ao longo do texto respeitaremos as nomenclaturas e terminologias presentes nos documentos nas citações literais, até mesmo para dar visibilidade às transformações dos modelos explicativos sobre a deficiência. 
humanos, ou seja, a cessão de professores da rede pública para a rede privada; a partilha também da responsabilidade com a comunidade para baratear os custos, mas também para a efetivação do direito à educação.

Em outras palavras, mesmo em um cenário político de forte influência das diretrizes políticas internacionais, cujo foco era a organização e universalização da Educação Básica, como estratégia da chamada "inclusão social", e posteriormente as diretrizes para escolarização dos alunos com deficiência no sistema regular de ensino, as tensões políticas internas na elaboração da Política de 1994 mantêm um paradigma de integração ao invés dos preceitos da inclusão, difundidos na Declaração de Salamanca, e mantém o protagonismo das instituições segregadas filantrópicas privadas na oferta educacional aos alunos da Educação Especial.

Nesta mesma ambiência, tivemos a aprovação da Lei de Diretrizes e Bases da Educação Nacional (LDBEN $n^{0}$ 9.394/96). Em linhas gerais, a educação foi, então, reorganizada em dois grandes níveis: a) "Educação Básica", que passou a abarcar educação infantil, ensino fundamental, ensino médio, educação de jovens e adultos e educação profissional; b) “educação superior”, que passou a abranger os cursos e programas sequenciais e os cursos de graduação, pós-graduação e extensão. Sobre a educaç̧ão de "pessoas portadoras de necessidades especiais", o capítulo dedicado à Educação Especial mantém o preferencialmente na rede regular de ensino presente na Constituição de 1988.

Ainda nos anos 90 do século passado, na contramão das conquistas efetivadas na Constituição de 1988, por conta das reformas do Estado que impactaram de maneira profunda a educação, o amplo direito foi sendo substituído pela prioridade do Ensino Fundamental, pela universalização do Ensino Médio e por políticas, desenvolvidas por meio de programas, com foco nos grupos sociais mais vulneráveis, a fim de assegurar o ingresso e a permanência na escola, como a obrigatoriedade de matrícula, a idade de ingresso, a duração dos níveis de ensino, os processos nacionais de avaliação de rendimento escolar, diretrizes curriculares nacionais, entre outros. No campo educacional foram atrelados de maneira mais incisiva às políticas os interesses do capital financeiro, da internacionalização da economia e da participação direta das proposições estabelecidas pelas instituições financeiras internacionais, em especial o Banco Mundial e o FMI, que condicionavam o suporte financeiro às nações subdesenvolvidas ou pobres à incorporação das políticas sociais por eles desenhadas (PEREIRA, 2008; OLIVEIRA, 2011; KASSAR, 2011; SOUZA; PLETSCH, 2017).

No apagar das luzes da década de 1990, em 1999, ocorre a homologação do Decreto ${ }^{\circ}$ 3.298 (BRASIL, 1999), que regulamentou dez anos depois a Lei no 7.853 de 1989 (BRASIL, 
1989), que institui a Política Nacional para a Integração da Pessoa Portadora de Deficiência. Este documento consolidou as normas de proteção e sistema de cotas e, no âmbito da educação, instaurou a educação especial como modalidade escolar transversal em todos os níveis, obrigatória em estabelecimentos públicos de ensino, preferencialmente na rede regular, e, ainda, “a matrícula compulsória em cursos regulares de estabelecimentos públicos e particulares de pessoa portadora de deficiência capazes de se integrar na rede regular de ensino" (BRASIL, 1989). Contudo, também reiterou "a inserção, no sistema educacional, das escolas ou instituições especializadas públicas e privadas”, e ainda tratou da necessidade de serviços "em escolas especializadas exclusivamente quando a educação das escolas comuns não puder satisfazer as necessidades educativas ou sociais do aluno ou quando necessário ao bem-estar do educando" (BRASIL, 1989). Neste rol de contradições entre os avanços sociais e a permanência de dispositivos tutelares, este decreto ainda era pautado no modelo médico de deficiência, trazendo questões sobre a normalidade pelo pressuposto da incapacidade orgânica na definição da deficiência: “[...] incapacidade para o desempenho de atividade, dentro do padrão considerado normal para o ser humano" (BRASIL, 1999).

Mesmo que pautado pelo modelo médico de deficiência, um importante passo desse decreto-lei foi a instituição do Conselho Nacional dos Direitos da Pessoa Portadora de Deficiência (Conade), com o objetivo de facilitar a descentralização do poder e a administração pública, estabelecendo uma interface entre a sociedade civil e o poder público. Esse Conselho representou uma maneira de a sociedade civil poder participar com voz de decisão em políticas que concernem aos grupos que elas representam e lutar mais ativamente na garantia da implementação da Política Nacional de Integração da Pessoa Portadora de Deficiência (SOUZA, 2013).

\section{Educação inclusiva como princípio dos Direitos Humanos para a educação de pessoas com deficiência}

Em 2001, foram instituídas as Diretrizes Nacionais para Educação Especial na Educação Básica (BRASIL, 2001a), nas quais a Educação Especial foi assumida como uma modalidade da educação escolar com recursos e serviços educacionais específicos, de caráter transversal, podendo ser complementar (serviços de suporte ao ensino comum como sala de recursos, profissional de apoio e ensino itinerante), suplementar (currículo enriquecido ou aceleração educacional para os alunos com altas habilidades/superdotação) ou até mesmo 
substitutiva (escola ou classe especial), “de modo a garantir a educação escolar e promover o desenvolvimento das potencialidades dos educandos que apresentam necessidades educacionais especiais" (BRASIL, 2001, Art. $3^{\circ}$ ). Este documento oficializou em nosso país os termos "educação inclusiva", mesmo que mantendo a possibilidade da Educação Especial como modalidade substitutiva em redes paralelas ao ensino regular e o repasse de verbas e recursos humanos para instituições privadas por meio das parcerias público-privadas, o que na análise de Lima e Mendes (2006) acaba não potencializando a adoção de uma política de educação inclusiva. As estatísticas da época corroboram com essa afirmação, pois em 2001, 59\% das matrículas se concentravam em escolas especiais, a maioria filantrópicas (BRASIL, 2001a).

Em relação ao público da Educação Especial, assim como na Declaração de Salamanca, há a denominação de educandos com necessidades educacionais especiais, que além de abarcar os alunos com deficiência, transtornos globais do desenvolvimento e altas habilidades/superdotação, elege os alunos com outros tipos de dificuldades de aprendizagem. Como podemos depreender, o termo necessidades educacionais especiais ampliou enormemente o público da Educação Especial sem evidenciar como seriam realizadas as avaliações e que equipe técnica ficaria responsável por tal ação, por exemplo, para definir quem seriam os sujeitos com dificuldades acentuadas de aprendizagem.

O documento prevê que para esta categoria a escola poderia, inclusive, criar classes especiais que devem ser transitórias. No entanto, considerando que historicamente muitos alunos foram e continuam sendo avaliados como alunos com dificuldades de aprendizagem e até mesmo com deficiência intelectual, essa classificação pode contribuir para ampliar o número de crianças avaliadas como tendo dificuldades acentuadas de aprendizagem, as quais podem ser segregadas das turmas comuns simplesmente por não se enquadrarem no modelo de aluno cartesiano, ideal (SCHNEIDER, 1977; FERREIRA, 1995; KASSAR, 2002; SANTOS, 2006). Infelizmente, essas práticas e políticas ainda não foram superadas apesar dos avanços legais e conceituais sobre a diferença humana. Pesquisa recente de Paiva (2017), evidenciou que muitas crianças continuam sendo avaliadas pelas próprias escolas como tendo deficiência intelectual e, uma vez identificadas como tal, o rótulo e o estigma permanecem e parte significativa evade da escola. Em nível internacional, Artiles e Kozleski (2019), em pesquisa realizada nos Estados Unidos, verificaram que alunos pobres, negros e latinos eram os mais avaliados como tendo problemas de aprendizagem e encaminhados a serviços especializados. Esses estudos corroboram com a ideia de que o modelo biomédico e da homogeneidade humana continuam presentes nas práticas, discursos e na cultura escolar. 
De fato, a década de 2000 foi marcada pela ampliação do tensionamento entre o desenvolvimento de políticas de enfrentamento à pobreza referenciadas socialmente e políticas alinhadas ao capital financeiro. Logo no início o Governo de Luís Inácio Lula da Silva, em 2003, tinha como meta "combater as mazelas socioeconômicas características da parcela de baixo poder aquisitivo da população e, dessa forma, promover condições de inclusão social a todos os segmentos da sociedade, em especial aos que se encontram em situaç̧ão de desvantagem” (SOARES, 2010, p. 31).

É nesse período que a questão da pessoa com deficiência passa a ser pautada pela pasta dos Direitos Humanos, vinculada à Presidência da República. Deste tempo, merece destaque a ratificação da Convenção sobre os Direitos da Pessoa com Deficiência e seu Protocolo Facultativo (CDPD) da ONU, em 2009; a transformação da Corde em constituição da Subsecretaria Nacional da Promoção dos Direitos das Pessoas com Deficiência (SNPD/SDH), em novembro de 2009; e, a formulação do Programa Social de Inclusão das Pessoas com Deficiência (2007) e do Plano Nacional dos Direitos da Pessoa com Defíciência "Viver sem Limites 2011-2014", em diálogo com as metas dos Objetivo do Milênio (ODM/ONU), que articulavam estratégias intersetoriais de enfrentamento da deficiência/pobreza, tendo como principais eixos: acessibilidade, educação, assistência e saúde; a pessoa com deficiência (cidadão coletivo) muda de lugar no âmbito dos direitos e da política (SOUZA, 2017).

Em consonância com a Convenção sobre os Direitos das Pessoas com Deficiência da ONU, em 2015, o governo brasileiro promulgou o Decreto $\mathrm{n}^{\circ} .6 .949$, de 25 de agosto de 2009, pela Lei $n^{0}$ 13.146, de 06 de julho de 2015, mais conhecida como Lei Brasileira de Inclusão da Pessoa com Deficiência (LBI). A LBI representa um avanço extraordinário para a garantia dos direitos educacionais e sociais de pessoas com deficiência ao "assegurar e promover, em condições de igualdade, o exercício dos direitos e das liberdades fundamentais por pessoa com deficiência, visando à sua inclusão social e cidadania” (BRASIL, 2015, p. 1). A LBI apresenta, também, um conjunto de conceitos e ações em diferentes áreas. Neste artigo, destacamos a ideia de acessibilidade e suas várias definições, que na análise de Isabel Maior (2020) precisa ser compreendida como um Direito Humano, conforme já sinalizamos anteriormente. Também destacamos o capítulo IV destinado à educação, que assegura um "sistema educacional inclusivo em todos os níveis e aprendizado ao longo de toda a vida, de forma a alcançar o máximo desenvolvimento possível de seus talentos e habilidades físicas, sensoriais, intelectuais e sociais, segundo suas características, interesses e necessidades de aprendizagem" (art. 27).

RIAEE - Revista Ibero-Americana de Estudos em Educação, Araraquara, v. 16, n. esp. 2, p. 1286-1306, maio 2021. e-ISSN: 1982-5587 
Ainda no campo educacional, já no primeiro ano do governo, houve iniciativas de construção de políticas públicas efetivadas por meio de programas esparsos e por adesão dos entes federativos, focando a educação inclusiva como meta para a escolarização de pessoas com deficiência. Dentre os programas destacamos o Programa Federal Educação Inclusiva: direito à diversidade, que já tinha como foco a formação de gestores e professores pelo modelo de municípios-polo e multiplicadores (PLETSCH, 2011). Outros programas foram incorporados, em 2007, no escopo do Plano de Desenvolvimento da Educação (PDE), conforme Meta IX do Compromisso Todos pela Educação: “Garantir o acesso e permanência das pessoas com necessidades educacionais especiais nas classes comuns do ensino regular, fortalecendo a inclusão educacional nas escolas públicas”. Entre outras medidas, partindo da premissa da "diversidade na igualdade como fundamento primeiro do ato educativo", propôs "arranjos educativos específicos nos quais se promove o desenvolvimento humano de todos e de cada um" (BRASIL, 2007a, p. 37).

No bojo do PDE, o governo lanç,ou, em setembro de 2007, uma proposta de "Política Nacional de Educação Especial na Perspectiva da Educação Inclusiva” (BRASIL, 2007a), propondo o fim dos serviços educacionais especializados em escolas e/ou classe especial em instituições filantrópicas, comunitárias e em todas as demais destinadas somente ao atendimento especializado. Essa proposta recebeu inúmeras críticas e a pressão das instituições filantrópicas privadas segregadas fizeram com que, em novembro, por meio do decreto presidencial $n^{0} 6.253$ (BRASIL, 2007b), se continuasse admitindo a distribuição de recursos do Fundo de Manutenção e Desenvolvimento da Educação Básica e de Valorização dos Profissionais da Educação (FUNDEB) para instituições comunitárias, confessionais ou filantrópicas com atuação exclusiva na educação especial.

Por isso, em janeiro de 2008, a SEESP apresentou uma "nova" versão da "Política Nacional de Educação Especial na Perspectiva da Educação Inclusiva", agora prevendo o atendimento especializado em salas de recursos e centros especializados de referência (BRASIL, 2008). A política de 2008 apresenta a educação inclusiva como "uma ação política, cultural, social e pedagógica, desencadeada em defesa do direito de todos os alunos de estarem juntos, aprendendo e participando, sem nenhum tipo de discriminacãao", entendendo-a no campo dos Direitos Humanos que compreende a deficiência na perspectiva social e “conjuga igualdade e diferença como valores indissociáveis, e que avança em relação à ideia de equidade formal ao contextualizar as circunstâncias históricas da produção da exclusão dentro e fora da escola" (BRASIL, 2008, p. 1). Prevê a matrícula de todos os alunos com deficiência, transtornos globais do desenvolvimento e altas habilidades na rede regular de 
ensino, com suporte do Atendimento Educacional Especializado (AEE) a ser oferecido de forma complementar (para alunos com deficiência e transtornos globais do desenvolvimento) ou suplementar (para alunos com altas habilidades/superdotação) no contraturno das atividades escolares. Esse alunado é assim definido:

1. Pessoa com deficiência aquela que tem impedimentos de longo prazo, de natureza física, mental ou sensorial que, em interação com diversas barreiras, podem ter restringida sua participação plena e efetiva na escola e na sociedade.

2. Estudantes com transtornos globais do desenvolvimento são aqueles que apresentam alterações qualitativas das interações sociais recíprocas e na comunicação, um repertório de interesses e atividades restrito, estereotipado e repetitivo. Incluem-se nesse grupo estudantes com autismo, síndromes do espectro do autismo e psicose infantil.

3. Estudantes com altas habilidades/superdotação demonstram potencial elevado em qualquer uma das seguintes áreas, isoladas ou combinadas: intelectual, acadêmica, liderança, psicomotricidade e artes, além de apresentar grande criatividade, envolvimento na aprendizagem e realização de tarefas em áreas de seu interesse (BRASIL, 2008, p. 11).

Nesta Política os sistemas de ensino eram orientados a transformarem-se em sistemas educacionais inclusivos, já em sintonia com os princípios dos Direitos Humanos da Convenção sobre os Direitos das Pessoas com Deficiência (CDPD). Por isso, retirou-se do documento o foco da modalidade substitutiva da Educação Especial, na esteira de outros documentos e programas que vinham sendo implementados neste governo.

\section{Direitos Humanos em risco: o desmonte da proposta de educação inclusiva}

No ano de 2016, vivemos um golpe de Estado que destituiu a presidenta eleita democraticamente, Dilma Rousseff. Deste processo, assumiu o governo, o até então vicepresidente Michel Temer que, redefiniu o Plano de Governo com a apresentação do projeto "Ponte para o Futuro", no qual previa a reestruturação de várias áreas, em especial as políticas sociais. Neste processo teve início a chamada "atualização" da Política Nacional de Educação Especial numa Perspectiva Inclusiva. Mas, com a baixa popularidade de seu governo e falta de articulação política, o processo não avançou.

É preciso demarcar que foi durante o governo Temer que foi instituída a Lei $n^{\circ} 13.409$, de 28 de dezembro de 2016, que alterou a Lei $\mathrm{n}^{\circ}$. 12.711, de 29 de agosto de 2012, a qual dispõe sobre a reserva de vagas para pessoas com deficiência nos cursos técnicos de nível médio e superior das instituições federais de ensino. Essa mudança tem ampliado o número de matrículas de pessoas com deficiência na Educação Superior brasileira (CABRAL, 
ORLANDO; MELETTI, 2020). Paralelamente, o mesmo governo extinguiu o Programa Incluir, considerado fundamental para as ações de acessibilidade nas universidades federais (MELO; ARAÚJO, 2018).

$\mathrm{Na}$ esteira dos acontecimentos políticos, vimos o avanço dos discursos conservadores de extrema direita e a intensificação dos disparos de fake news que, em 2018, contribuíram para eleger Jair Bolsonaro para o cargo de presidente da república. Logo na posse a primeira dama Michele Bolsonaro fez o discurso em Libras, comovendo os desavisados que não sabiam o que estava por vir. Ainda em seu primeiro ano de governo o cargo de intérprete de Libras, por exemplo, foi extinto nas carreiras federais, obrigando assim as Universidades, sobretudo, a realizarem contratações via terceirização.

Em seu segundo ano de governo, durante a pandemia provocada pelo novo “coronavírus" (SARS-CoV-2), declarada pela Organização Mundial da Saúde em 11 de março de 2020, o governo federal apresentou no dia 30 de setembro de 2020 o Decreto 10.502, que institui a Política Nacional de Educação Especial: Equitativa, Inclusiva e com Aprendizagem ao Longo da Vida. Entre as mais de 200 notas de repúdio e moções criticando o decreto vindas de pesquisadores, associações científicas, organizações de famílias de pessoas com deficiência, associações de pessoas com deficiências, confederação dos trabalhadores na educação, congressistas e setores do Ministério Público Federal (ABRASCO, 2020; AMPID, 2020; ANPED-ABPEE, 2020; INSTITUTO ALANA, 2020; entre outros), destacam-se três aspectos.

O primeiro é que a proposta do atual governo rompe com o princípio de educação inclusiva no campo dos Direitos Humanos ao defender fortemente a segregação por meio de escolas especiais, as quais no nosso país, são, em sua maioria, instituições filantrópicas privadas. O segundo se refere ao papel do Estado como fornecedor de educação às pessoas com deficiência, na medida em que a nova política federal institui o primado da família na escolha do tipo de educação a ser oferecida aos seus filhos, segundo o discurso neoliberal da soberania do consumidor em eleger livremente o melhor provedor de serviço educacional (SILVA et al., 2020; PEREIRA; PLETSCH, 2021, no prelo), dessa forma desresponsabilizando o Estado pela educação de crianças e jovens com deficiência. $\mathrm{O}$ terceiro se refere a problemas de compreensão conceitual. Por exemplo, a Educação Especial e a educação inclusiva são apresentadas como perspectivas educacionais distintas. Em nosso entendimento, a Educação Especial é uma modalidade de ensino transversal com técnicas e recursos especializados próprios que atua de forma colaborativa com a educação básica e a superior para garantir a inclusão e a acessibilidade educacional de pessoas com 
deficiência (PLETSCH, 2020). Já a educação inclusiva é um paradigma de política pública que, imerso nos pressupostos dos Direitos Humanos, visa induzir o acesso à educação aos grupos que historicamente sofrem processos de exclusão de direitos e por isso são apartados do direito de aprender em escolas de sua comunidade, junto aos pares de sua idade em um meio constituído pela/na diversidade.

O texto da Política Nacional de Educação Especial: Equitativa, Inclusiva e com Aprendizagem ao Longo da Vida (BRASIL, 2020a) toma como base dados oficiais como, por exemplo, as matrículas insuficientes no Atendimento Educacional Especializado (AEE) e a falta de qualificação dos professores para atuar com esses alunos para justificar e defender a segregação. O que o Ministro do Supremo Tribunal Federal (STF), em medida cautelar, de $1^{\circ}$ de dezembro de 2020, suspendendo o decreto 10.502 que institui a referida política, afirma que a regra não pode ser usada para "uma involução na proteção de direitos desses indivíduos", referindo-se às pessoas com deficiências (p. 24).

Outro aspecto que chama atenção no documento, apesar do reconhecimento da Educação Especial como área de conhecimento na CAPES e no CNPq, é a negação de toda produção científica acumulada nos últimos anos sobre os avanços legais, pedagógicos e científicos envolvendo a escolarização de pessoas com deficiência, transtornos globais do desenvolvimento e altas habilidades/superdotação. Neste sentido, esta proposta representa um retrocesso ao defender amplamente o acesso a instituições segregadas filantrópicas privadas, a qual se pauta, sobremaneira, em ações tutelares (que se opõem às pautas políticas dos movimentos sociais desde tempos da constituinte e da participação decisória das pessoas com deficiência) e no modelo médico de compreensão da deficiência.

Dia onze de dezembro de 2020 iniciou o julgamento no STF sobre a suspensão do Decreto 10.502, com previsão para finalizar dia 18 de dezembro do mesmo ano. As organizações científicas como a Associação Nacional de Pós-Graduação e Pesquisa em Educação (ANPED) e a sociedade civil se mobilizaram e mais de 20 pedidos de ingresso de amici curiae (amigos da corte) foram apresentados ao STF. No âmbito da defesa pela suspensão do decreto criou-se o movimento Coalizão Brasileira pela Educação Inclusiva, que representa mais de 40 entidades da sociedade civil, incluindo a Associação Nacional de Membros do Ministério Público de Defesa dos Direitos das Pessoas com Deficiência e dos Idosos (AMPID), em defesa aos princípios da política de educação inclusiva, conforme disposto na CDPD.

Também foram apresentadas 8 amici curiae em defesa do decreto, dentre os quais o da Federação Nacional de Educação e Integração dos Surdos (FENEIS), que compreende que os 
direitos dos surdos foram ampliados com o Decreto 10.502. Não é novidade a defesa de espaços educacionais segregados em escolas especiais bilíngues pelos surdos, pois acreditam que, como grupo linguístico minoritário usuário de Língua Brasileira de Sinais (LIBRAS), somente agrupados com os seus pares é possível desenvolver a cultura e a identidade surda. $\mathrm{Na}$ sustentação oral realizada na ADI 6590 STF - amicus curiae pelo representante da FENEIS e da Confederação Brasileira de Desportos de Surdos (SBDS) ${ }^{6}$ houve a defesa de que os surdos se entendem como uma comunidade linguística com identidade e cultura própria, questionando, inclusive, o fato de serem pessoas com deficiência.

No entanto, contrário a essa ideia, para iniciar os seus argumentos, usa-se o lema internacional da luta das pessoas com deficiências: "Nada sobre nós sem nós". A ideia de que a educação bilíngue é uma modalidade educacional não está de acordo com a LDBEN/1996, que reconhece a Educação Especial como modalidade, a qual abarcaria a educação bilíngue. Igualmente, é importante sinalizar que os direitos educacionais e linguísticos das pessoas surdas já são garantidos pelo ordenamento jurídico nacional e constam na LBI: "IV - oferta de educação bilíngue, em Libras como primeira língua e na modalidade escrita da língua portuguesa como segunda língua, em escolas e classes bilíngues e em escolas inclusivas" (BRASIL, 2015). Será que vale a pena defender um decreto que visivelmente ataca os Direitos Humanos da maioria da população com deficiência no Brasil somente para reforçar um direito já conquistado?

Os defensores do decreto também sinalizam que uma parcela da população com deficiência não se beneficiará do ensino ministrado em escolas comuns, pois demandam programas específicos, como comunicação alternativa e outros recursos. Além de discriminatória essa visão é determinista e, até mesmo, capacitista, sobre as possibilidades do desenvolvimento humano. Temos investigado os processos educacionais de crianças com deficiência múltipla não oralizados desde 2012 e, atualmente, pesquisamos a escolarização e o desenvolvimento de crianças com sequelas severas provocadas pela síndrome congênita do zika vírus (SCZV). Os resultados de nossas investigações têm evidenciado que a escola afeta de forma positiva na participação e no desenvolvimento dessas crianças, desde que sejam oferecidos os devidos suportes e apoios pedagógicos articulados, quando necessário, de forma intersetorial, com a saúde e a assistência social (ROCHA, 2018).

Uma de nossas hipóteses, em processo de investigação por uma equipe interdisciplinar com mais de 50 pesquisadores da UFRRJ, UERJ, PUC-RJ, FIOCRUZ (ENSP e IFF), é a de

\footnotetext{
${ }^{6}$ Disponível em: https://www.youtube.com/watch?v=qv4CQV9Arco. Acessado em: 13 dez. 2020.
} 
que a matrícula destas crianças em turmas comuns de ensino, com os devidos suportes, favorece o seu bem-estar e, consequentemente, qualifica a sua escolarização e as suas condições de saúde. Nesse sentido, propor ações intersetoriais tomando como referência o modelo social de deficiência e a funcionalidade humana para o desenvolvimento das crianças com deficiências mais severas (aquelas que, segundo o decreto, não se beneficiariam da escola comum) requer repensar a função social da escola como instituição que, ao acolher a diversidade, amplia as possibilidades de desenvolvimento dos alunos (DAINEZ; SMOLKA, 2019; PLETSCH; ARAUJO; ROCHA, 2020), dessa forma contribuindo com o desenvolvimento de uma sociedade mais solidária, pautada na justiça social, aspecto central para o fortalecimento da democracia e de uma cultura de Direitos Humanos

Para finalizar, não podemos deixar de ressaltar que das 1,3 milhão de matrículas de alunos com deficiência, transtornos globais do desenvolvimento e/ou altas habilidades/superdotação no Brasil, de acordo com o Educacenso de 2019, 92\% estavam efetivadas em turmas comuns do ensino regular, majoritariamente no sistema público de ensino (BRASIL, 2019). Neste contexto, as argumentações e posições apresentadas ao longo deste artigo indicam que o desafio é qualificar e ampliar o financiamento da escola pública brasileira de forma a acolher a diversidade e a pluralidade que a constituem, "não cabendo ao Poder Público recorrer aos institutos das classes ou escolas especializadas para furtar-se às providências de inclusão educacional de todos os estudantes" (TOFFOLI, 2020, p. 24). Concluímos este artigo reiterando nossa posição por uma educação pública, universal, gratuita, referendada socialmente e pelos princípios dos Direitos Humanos. Entendendo que a via mais potente para o desenvolvimento da pessoa com deficiência é na convivência com os demais e vice-versa, pois é na interação com a diferença que nos humanizamos.

AGRADECIMENTOS: Agradecemos o financiamento do Conselho Nacional de Desenvolvimento Científico e Tecnológico (CNPq); Fundação de Amparo à Pesquisa do Estado do Rio de Janeiro (FAPERJ) (Edital Jovem Cientista do Nosso Estado e Edital Grupos Emergentes Processo E-26/010.002186/2019; Edital Auxílio Pesquisador Recém-contratado 2019 - Processo E-26/211.321/2019; Programa de Incentivo à Produção Científica, Técnica e Artística-Prociência Faperj/UERJ). 


\section{REFERÊNCIAS}

ARTILES, A. J.; KOZLESKI, E. B. Promessas e trajetórias da Educação Inclusiva: notas críticas sobre pesquisas futuras voltadas a uma ideia venerável. Revista Brasileira de Educação Especial, v. 25, n. 3, 2019.

ABRASCO. Nota de repúdio ao Decreto n. 10.502, de 30 de setembro de 2020, que institui a Política Nacional de Educação Especial. 2020. Disponível em:

https://www.abrasco.org.br/site/noticias/nota-de-repudio-ao-decreto-no-10-502-de-30-desetembro-de-2020-que-institui-a-politica-nacional-de-educacao-especial/52894/. Acesso em: 25 out. 2020.

AMPID-Associação Nacional dos Membros do Ministério Público de Defesa dos Direitos das Pessoas com Deficiência e Idosos. Nota de repúdio contra o Decreto n. 10.502. 2020.

Disponível em: https://ampid.org.br/site2020/nota-publica-de-repudio-ao-decreto-no-10-5022020/. Acesso em: 25 out. 2020.

ANPED-ABPEE. Repúdio sobre o Decreto n. 10.502, de 30 de setembro de 2020, que institui a Política Nacional de Educação Especial: equitativa, inclusiva e com aprendizado ao longo da vida. 2020. Disponível em: https://anped.org.br/news/anped-e-abpee-denunciamretrocessos-em-nova-politica-de-educacao-especial-lancada-pelo-governo. Acesso em: 25 out. 2020 .

BRASIL. Constituição (1988). Constituição da República Federativa do Brasil. Brasília, DF: Senado, 1988.

BRASIL. Lei n. 7.853, de 24 de outubro de 1989. Dispõe sobre o apoio às pessoas portadoras de deficiência, sua integração social, sobre a Coordenadoria Nacional para Integração da Pessoa Portadora de Deficiencia - Corde, institui a tutela jurisdicional de interesses coletivos ou difusos dessas pessoas, disciplina a atuação do Ministério Público, define crimes, e dá outras providencias. Brasília, 25 de outubro de 1989. Disponível em:

http://www.planalto.gov.br/ccivil_03/leis/17853.htm. Acesso em: 10 jul. 2020.

BRASIL. Política Nacional de Educação Especial. Brasília: SEESP, 1994.

BRASIL. Lei n. 9.394, de 20 de dezembro de 1996. Lei de Diretrizes e Bases da Educação Nacional. Diário Oficial da União: Seção 1, Brasília, DF, n. 248, p. 27833, 23 dez. 1996.

BRASIL. Decreto n. 3.298, de 20 de dezembro de 1999. Regulamenta a Lei $n^{0} 7.853$, de 24 de outubro de 1989, dispõe sobre a Política Nacional para a Integração da Pessoa Portador de Deficiência, consolida as normas de proteção, e dá outras providências. Diário Oficial da União, Brasília, 1999. Disponível em:

http://www.planalto.gov.br/ccivil_03/decreto/d3298.htm. Acesso em: 10 jul. 2020.

BRASIL. Resolução n. 2, de 11 de setembro de 2001. Institui as Diretrizes Nacionais da Educação Especial na Educação Básica. Brasília: Ministério da Educação/ SEESP, 11 de setembro de 2001. Disponível em: http://portal.mec.gov.br/cne/arquivos/pdf/CEB0201.pdf. Acesso em: 10 jul. 2020.

BRASIL. Educacenso. Brasília, DF: INEP, 2001a. 
BRASIL. Ministério da Educação. Decreto 3.956, de 8 de outubro de 2001. Promulga a Convenção Interamericana para a Eliminação de Todas as Formas de Discriminação contra as Pessoas Portadoras de Deficiência. Brasília, DF: MEC, out. 2001a. Disponível em: http://www.planalto.gov.br/ccivil_03/decreto/2001/d3956.htm. Acesso em: 10 jul. 2020.

BRASIL. Decreto n. 6.094, de 24 de abril de 2007. Dispõe sobre a implementação do Plano de Metas Compromisso Todos pela Educação, pela União Federal, em regime de colaboração com Municípios, Distrito Federal e Estados, e a participação das famílias e da comunidade, mediante programas e ações de assistência técnica e financeira, visando a mobilização social pela melhoria da qualidade da Educação Básica. Brasília, 2007. Disponível em: http://www.planalto.gov.br/ccivil_03/_ato2007-2010/2007/decreto/d6094.htm. Acesso em: 10 jul. 2020.

\section{BRASIL. Política Nacional de Educação Especial na perspectiva da Educação Inclusiva - versão preliminar. Brasília, setembro de 2007a.}

BRASIL. Decreto n. 6.253, de 13 de novembro de 2007. Dispõe sobre o Fundo de Manutenção e Desenvolvimento da Educação Básica e de Valorização dos Profisssionais da Educação - FUNDEB, regulamenta a Lei no 11.494, de 20 de junho de 2007, e dá outras providências. Brasília, 2007b. Disponível em:

http://www.planalto.gov.br/ccivil_03/_ato2007-

2010/2007/decreto/d6253.htm\#: :text=DECRETO $\% 20 \mathrm{~N} \% \mathrm{C} 2 \% \mathrm{BA} \% 206.253 \% 2 \mathrm{C} \% 20 \mathrm{DE} \% 2$ 013\%20DE\%20NOVEMBRO\%20DE\%202007.\&text=Disp $\% \mathrm{C} 3 \%$ B5e $\% 20$ sobre $\% 20 \mathrm{o} \% 20 \mathrm{~F}$ undo $\% 20 \mathrm{de}, 2007 \% 2 \mathrm{C} \% 20 \mathrm{e} \% 20 \mathrm{~d} \% \mathrm{C} 3 \% \mathrm{~A} 1 \% 20$ outras $\% 20$ provid $\% \mathrm{C} 3 \% \mathrm{AAncias}$. Acesso em: 10 jul. 2020.

BRASIL. Política Nacional de Educação Especial na perspectiva da Educação Inclusiva. Brasília, DF, jan. 2008.

BRASIL. Lei n. 10.753, de 30 de outubro de 2003. Institui a Política Nacional do Livro. Brasília, DF, 31 out. 2003. Disponível em: https://www2.camara.leg.br/legin/fed/lei/2003/lei10753-30-outubro-2003-497306-publicacaooriginal-1-pl.html. Acesso em: 10 jul. 2020.

BRASIL. Lei n. 13.146, de 6 de julho de 2015. Institui a Lei Brasileira de Inclusão da Pessoa com Deficiência (Estatuto da Pessoa com Deficiência). Brasília, DF, 7 jul. 2015. Disponível em: http://www.planalto.gov.br/ccivil_03/_ato2015-2018/2015/lei/113146.htm. Acesso em: 10 jul. 2020.

BRASIL. Educacenso: resumo técnico. Brasília, DF: INEP, 2019.

BRASIL. Decreto n. 10.502, de 30 de setembro de 2020. Institui a Política Nacional de Educação Especial: Equitativa, Inclusiva e com Aprendizado ao Longo da Vida. Brasília, DF, 01 out. 2020. Disponível em_https://www.in.gov.br/en/web/dou/-/decreto-n-10.502-de-30-desetembro-de-2020-280529948. Acesso em: dezembro de 2020.

BRASIL. Ministério da Educação. Secretaria de Modalidades Especializadas de Educação. Política Nacional de Educação Especial: Equitativa, Inclusiva e com Aprendizagem ao Longo da Vida. Brasília, DF: MEC/SEMESP, 2020. Disponível em:

RIAEE - Revista Ibero-Americana de Estudos em Educação, Araraquara, v. 16, n. esp. 2, p. 1286-1306, maio 2021. e-ISSN: 1982-5587 
https://www.gov.br/mec/pt-br/assuntos/noticias/mec-lanca-documento-sobre-implementacaoda-pnee-1/pnee-2020.pdf. Acesso em: 10 dez. 2020.

BRASIL. Medida Cautelar na ação direta de Inconstitucionalidade 6.590. Distrito Federal. Disponível em: http://portal.stf.jus.br/processos/detalhe.asp?incidente=6036507. Acesso em: 10 dez. 2020.

CABRAL, V. N.; ORLANDO, R. M.; MELETTI, S. M. F. O Retrato da Exclusão nas Universidades Brasileiras: os limites da inclusão. Revista Educação e Realidade, Porto Alegre, v. 45, n. 4, 2020. DOI: https://doi.org/10.1590/2175-6236105412

DAINEZ, D.; SMOLKA, A. L. B. A função social da escola em discussão, sob a perspectiva da educação inclusiva. Revista Educação e Pesquisa, v. 45, p. 1-18, 2019. DOI: http://dx.doi.org/10.1590/s1678-4634201945187853

DINIZ, D.; BARBORA, L.; SANTOS, W. R. Deficiência, direitos humanos e justiça. Revista Internacional de Direitos Humanos, v, 6, n 11, p. 65-77, 2009.

INSTITUTO ALANA. A inconstitucionalidade do Decreto n. 10.502/2020. Disponível: https://alana.org.br/. Acesso em: 10 dez. 2020

FERREIRA, J. R. A exclusão da diferença. 3. ed. Piracicaba, SP: Editora Unimep, 1995.

GOHN, M. G. O Protagonismo da sociedade civil. Movimentos sociais, ONGs e redes solidárias. São Paulo: Cortez, 2005. 120 p.

KASSAR, M. C. M. Políticas nacionais de educação inclusiva - discussão crítica da Resolução 02/2001. Ponto de Vista (UFSC), Florianópolis, v. 1, n.3/4, p. 13-25, 2002. Disponível em: https://periodicos.ufsc.br/index.php/pontodevista/article/view/1300. Acesso em: 13 dez. 2020.

KASSAR, M. C. M. Percursos da constituição de uma política brasileira de Educacạao Especial Inclusiva. Revista Brasileira de Educação Especial, Marília, v. 17, p. 41-58, maio/ago. 2011.

KASSAR, M. C. M. Escola como espaço para a diversidade e o desenvolvimento humano. Educação e Sociedade, v. 37, n. 137, p. 1223-1240, 2016. DOI: https://doi.org/10.1590/es0101-73302016157049

KASSAR, M. C. M.; REBELO, A. S.; OLIVEIRA, R. T. C. Embates e disputas na política nacional de Educação Especial brasileira. Educação e Pesquisa, São Paulo, v. 45, e217170, 2019. DOI: http://dx.doi.org/10.1590/S1678-4634201945217170

LANNA JÚNIOR, M. C. M. História do Movimento Político das Pessoas com Deficiência no Brasil. Brasília, DF: Secretaria de Direitos Humanos. Secretaria Nacional de Promoção dos Direitos da Pessoa com Deficiência, 2010. 443 p.

LAPLANE, A.; CAIADO, K.; KASSAR, M. As relações público-privado na Educação Especial: tendências atuais no Brasil. Revista Teias, v. 17, n. 46, 2016. Disponível em: 
https://www.e-publicacoes.uerj.br/index.php/revistateias/article/view/25497/18546. Acesso em: 25 out. 2020 .

LIMA, S. R.; MENDES, E. G. Politicas nacionais para a educação das pessoas com deficiência. In: SIMPÓSIO INTERNACIONAL: O ESTADO E AS POLÍTICAS EDUCACIONAIS DO TEMPO PRESENTE, 5., 2009, Uberlândia. CD-ROM Anais. Uberlândia, MG: Universidade Federal de Uberlândia, 2009.

MAIOR, I. L. Pessoas com deficiência no contexto da pandemia do COVID-19. In: Palestra no III Congresso Nacional de Inclusão na Educação Superior e Educação Profissional Tecnológica. Disponível em: https://www.youtube.com/watch?v=TH1ZrfyPuwo. Acesso em: dezembro de 2020.

MAZZOTTA, M. Educação Escolar comum ou especial? São Paulo, SP: Pioneira Novos Umbrais, 1986.

MELO, F. R. L. V.; ARAÚJO, E. R. Núcleos de Acessibilidade nas Universidades: reflexões a partir de uma experiência institucional. Revista Psicologia Escolar e Educacional, v. esp., p. 57-66, 2018. DOI: https://doi.org/10.1590/2175-35392018046

MINTO, L. W. Globalização, transição democrática e educação (inter)nacional (1984...). 2012. Disponível em:

http://www.histedbr.fae.unicamp.br/navegando/periodo_transicao_democratica_intro.html. Acessado em: 13 dez. 2012.

OLIVEIRA, D. Das políticas de governo à politica de estado: reflexões sobre a atual agenda educacional brasileira. Educação e Sociedade, Campinas, v. 32, n. 115, p. 323-337, abr./jun. 2011.

PAIVA, C. O processo de avaliação e encaminhamento de alunos com deficiência intelectual para o atendimento educacional especializado. 2017. 140 f. Dissertação (Mestrado em Educação, Contextos Contemporâneos e Demandas Populares) - Universidade Federal Rural do Rio de Janeiro, Rio de Janeiro, 2017.

PEREIRA, J. M. M. O Banco Mundial como ator político, intelectual e financeiro 1944 2008. Rio de Janeiro: Civilização Brasileira, 2010. 502 p.

PEREIRA, J. M. M.; PLETSCH, M. D. A agenda educacional do Banco Mundial para pessoas com deficiência e o caso brasileiro. Revista Brasileira de Educação, 2021. No prelo.

PLETSCH, M. D. A dialética da inclusão/exclusão nas políticas educacionais para pessoas com deficiências: um balanço do governo Lula (2003-2010). Revista Teias, v. 12, n. 24, p. 39-55, jan./abr. 2011.

PLETSCH, M. D. O que há de especial na Educação Especial Brasileira? Momento Diálogos em Educação, v. 29, n. 1, p.1-15, 2020. DOI:

http://dx.doi.org/10.14295/momento.v29i1.9357

PLETSCH, M. D.; ARAUJO, P. C. A.; ROCHA, M. G. S. A importância de ações intersetoriais como estratégia para a promoção da escolarização de crianças com a síndrome 
congênita do zika vírus (SCZV). Revista Educação em Foco, Juiz de Fora, v. 25, n. 3, p. 193-210, set./dez. 2020. DOI: https://doi.org/10.22195/2447-524620202532924

ROCHA, M. G. S. Os sentidos e significados da escolarização de sujeitos com deficiência múltipla. 2018. 291 f. Tese (Doutorado em Educação) - Universidade Federal Rural do Rio de Janeiro, Nova Iguaçu, 2018.

SANTOS, R. A. Processos de escolarização e deficiência: trajetórias escolares singulares de ex-alunos de classe especial para deficientes mentais. 2006. $197 \mathrm{f}$, Tese (Doutorado em Educação) - Pontifícia Universidade Católica de São Paulo, São Paulo, 2006.

SILVA, G. F. et al. Educação Especial e diversidades: emergências atuais. Revista de Educação, Ciência e Cultura, v. 25, p. 7-14, 2020. DOI:

http://dx.doi.org/10.18316/recc.v25i1.6697

SOARES, M.T. N. Programa Educação Inclusiva Direito à Diversidade: Estudo de Caso sobre estratégia de multiplicação de políticas públicas. 2010. 126 f. Dissertação (Mestrado em Educação) - Universidade Federal da Paraíba, João Pessoa, 2010.

SCHNEIDER, D. Alunos excepcionais: um estudo de caso de desvio. In: VELHO, G. (Org.). Desvio e divergência: uma crítica da patologia social. 8. ed. Rio de Janeiro: Editora Jorge Zahar, 2003.

SOUZA, F. F. Políticas de educação inclusiva: análise das condições de desenvolvimento dos alunos com deficiência na instituição escolar. 2013. 297 f. Tese (Doutorado em Educação) - Universidade Estadual de Campinas, Campinas, 2013.

SOUZA, F. F. As pessoas com deficiência e a educação: políticas sociais e de educação inclusiva nos governos do PT (2003-2011). Agenda Social (UENF), v. 10, n. 1, p. 44-59, 2017.

SOUZA, F. F.; PLETSCH, M. D. A relação entre as diretrizes do Sistema das Nações Unidas (ONU) e as políticas de Educação Inclusiva no Brasil. Ensaio. Avaliação e Políticas Públicas em Educação, v. 97, p. 1-23, 2017. DOI: https://doi.org/10.1590/s010440362017002500887

UNESCO. Declaração de Salamanca sobre princípios, políticas e práticas na área das necessidades educativas especiais (1994) (BR/1998/PI/H/7). Brasília: UNESCO, 1998.

UNGA. Resolution A/RES/48/96, of 04 March 1994. Standard rules on the equalization of opportunities for persons with disabilities. General Assembly, 4 mar. 1994. 


\section{Como referenciar este artigo}

PLETSCH, M. D.; SOUZA, F. F. Educação comum ou especial? Análise das diretrizes políticas de educação especial brasileiras. Revista Ibero-Americana de Estudos em Educação, v. 16, n. esp. 2, p. 1286-1306, maio 2021. e-ISSN: 1982-5587. DOI: https://doi.org/10.21723/riaee.v16iesp2.15126

Submissão em: $15 / 12 / 2020$

Revisões requeridas em: 28/01/2021

Aprovado em: 03/03/2021

Publicado em: 01/05/2021 